\title{
User Satisfaction of Electric-Vehicles About Charging Stations (Home, Outdoor, and Workplace)
}

\author{
Iqbal H. Jebril ${ }^{a}$, Ma'mon Abu Hammad ${ }^{b}$, Ahmad R. Al Aboushi', Musa M. Salahd \\ Osamah Ibrahim Khalaf ${ }^{\mathrm{e}}$
}

${ }^{\mathrm{a}, \mathrm{b}}$ Mathematics Department, Al Zaytoonah University of Jordan, Jordan e-mail ${ }^{\text {a }}$ i.jebri@zuj.edu.jo

${ }^{\mathrm{c}}$ Mechanical Engineering Department, Al Zaytoonah University of Jordan, Jordan

${ }^{\mathrm{d}}$ Multimedia Technology, Department, Al Zaytoonah University of Jordan, Jordan

${ }^{\mathrm{e}}$ Al-NahrainNanorenewable Energy Research Centre, AI-NahrainUniversity,Baghdad, Iraq

Article History: Received: 10 November 2020; Revised 12 January 2021 Accepted: 27 January 2021; Published online: 5 April 2021

\begin{abstract}
This paper aims to investigate the user's satisfaction with electric cars about charging stations (home, outdoor, and workplace). The descriptive approach was used. 403 questionnaires was distributed to the study population, 349 questionnaires are Usable. The Data were analyzed using Amos. The study found that there is an impact on the satisfaction of electric vehicle users in Jordan. we recommends to reducing the time spent charging electric vehicles at external charging stations, and increasing the quality of the mechanisms used in charging electric cars.
\end{abstract}

Keywords: Electric-Vehicles, Charging Stations, and AMOS

\section{Introduction}

Today's electric cars are develop to a reliable and marketable product, the development of vehicle technology continues forward due to the environmental benefits that can be achieved by reduced total carbon dioxide emissions, and the reduction in emissions of fossil fuels that cause damage through greenhouse gas emissions and negatively affect the earth's climate. Moving towards the use of electric vehicles (EV) to reduce carbon emissions and fossil fuels is a good to solution the problem of climate change, and to increase overall energy efficiency. In this way, electric vehicles may contribute to improving electric power systems (Borges, et al., 2010).

In recent years, the dramatic increase in electric vehicles and charging stations has increased the quality of voltage and harmonic distortion affecting the electrical grid; electric vehicles have received great attention as an environmentally sustainable and cost-effective alternative to vehicles with an internal combustion engine (Capaso, et al., 2012).

Khan et al. (2018) developed an isolated smart micro grid connecting renewable energy sources and electric cars by controlling and stabilizing power flow in the grid. The power is to be transmits to electric car charging stations where hybrid and electric car batteries charge up. In this context, various standards for electric vehicle charging systems have been explored by many organizations around the world, as organizations consider safety, reliability, durability, rated power and cost of different charging methods, electric vehicle charging equipment plays an important role in its development, net workplace integration and daily use (Sbordone, et al., 2014).

This paper performs the literature review in the renewable energy sector to discover a gap in the power transmission to the EV charging station. However, previous studies found that AC power transmission is not effective for charging up electric-vehicles because it takes long due to usage of high power electronic components. Moreover, energy storage in capacitors depends on the size of metal plates and quality of material used for dielectric materials. Khan et al. (2018) conform that the desired voltage level of 585 VDC were attained at the car charging station. In addition, this paper deals with different type of EVs charging stations and investigates user satisfaction of electric-vehicles about charging stations (Home, Outdoor, and Workplace).

\section{Research Questions}

The research questions of this study are presented as follows:

Does charging stations of electric-vehicles effect positively on User satisfaction?

1.1 Does home charging stations of electric-vehicles effect positively on User satisfaction?

1.2 Does outdoor charging stations of electric-vehicles effect positively on User satisfaction? 
1.3 Does Workplace charging stations of electric-vehicles effect positively on User satisfaction?

\section{Research Objectives}

The main objective of this study is to examine the User satisfaction of electric-vehicles about charging stations. Specifically, the objectives are listed as follows:

1. To investigate the impact of home charging stations of electric-vehicles on User satisfaction

2. Know the impact of outdoor charging stations of electric-vehicles on User satisfaction.

3. To investigate the impact of Workplace charging stations of electric-vehicles on User satisfaction.

\section{Research Hypotheses}

The Null hypothesis: "There is no statistically significant effect in the charging station on the Satisfaction of electric vehicle users in Jordan."

The following sub hypotheses are divided into:

H1: There is no statistically significant effect at $(\alpha<0.05)$ for home charging stations on the satisfaction of electric vehicle users in Jordan.

H2: There is no statistically significant effect at $(\alpha<0.05)$ for external charging stations (gas stations) on the satisfaction of electric vehicle users in Jordan.

H3: There is no statistically significant effect at $(\alpha<0.05)$ for charging stations at Workplace on the satisfaction of electric vehicle users in Jordan.

\section{Literature Review}

Electric vehicles (EVs) historically predate gasoline vehicles, but have only received mainstream interest in the last decade (Eberle and Helmolt, 2010). In the 21st century, we are facing with the dual challenge of energy and environmental issues in the frame of sustainable transport development. In the foreseeable future, the large-scale utilization of EVs can largely reduce the fossil fuels usage and particulate emission (Xiang, et al., 2017). Electric vehicles (EVs) offer significant potential for increasing energy efficiency in transportation, reducing greenhouse gas emissions, and relieving reliance on foreign oil (Duvall, et al., 2007). EV charging increases the electric loads, and potentially amplifies the peak demand or creates new peaks in electricity demand (Kelly, et al., 2009).

Unlike gasoline or hydrogen fueling which only takes a few minutes, the charging process is normally much longer and could take up to hours. As a result, charging is more likely to happen at the end of a trip rather than in the middle of a trip. Furthermore, in addition of charging vehicles at public charging stations, EV owners can also have the option to charge at home. Therefore, traffic flow volume or vehicle ownership density does not necessarily represent demand for public charging infrastructure (Guan, et al., 2013).

Electric Vehicles such as electric cars or electric scooters have an electric engine that is powered using onboard batteries. EVs need to be plugged into power outlets for charging when its batteries are depleted (Iyengar, et al., 2016). The machines in the electric vehicles are powered up by batteries but currently batteries take longer to charge up so an engine needs to be running to store power at the batteries and support the vehicles in the hills and to maintain speed (Yong et al., 2015). To meet these requirements demands of the new technology investigated earlier and DC power flow is found most reliable and efficient for this task because it charges up batteries in very short time (Fan et al., 2015). The energy can be stored quickly in the vehicle batteries at the car charging station and by means of regenerative breaking when the vehicles stop. DC power charging up also improves the efficiency of the power flow in electric cars by supplying the required power to the AC electric machines being used in electric or hybrid cars by means of converters.

Generally, the charging station contains the charging stand, the charging cord, the connection plug, the power outlet, the protection system and the car connector, this configuration of the charging station varies from country to country according to the voltage, frequency, standards, and electrical net Workplace connection. The battery life and charging time of an electric vehicle are related to the characteristics of the charger, which must first ensure proper charging of the battery. Then a good charger must be reliable and efficient, combined with low cost, high energy density, low volume and weight. The charger inside the car allows owners to charge their cars wherever a suitable power source is available (Sbordone, et al., 2014).

Wang, et al., (2010) introduced a multi-objective extendable model on EVs charging stations distribution, taking into account the sustainable development of electric vehicles, charging station's features, the user's behavior, the distribution of charging demand, municipal planning and other factors. In addition, the convenience of using the charging infrastructure significantly affects the people's motivation to purchase EVs (Xue, et al., 2015). 
Cheng, et al., (2019) confirm that increasing the density of charging stations, lowering the charging price and shortening the charging time can effectively improve user satisfaction. Iyengar, et al., (2016) show that 80th percentile of EVs have at least 75\% battery level at the end of their charging session. Finally, we demonstrate the feasibility of our charging station and show that a solar installation proportional to the size of a parking lot adequately apportions available solar energy generated to the EVs serviced.

Sioshansi (2012) presents an analysis of individual drivers' plug-in hybrid electric vehicle charging patterns under various electricity pricing tariffs and compares the cost and emissions impacts of these charging patterns.

\section{Data Analysis}

The study population consists of all electric vehicle users in all the governorates of Jordan, while the study sample consisted of (403) electric vehicle users in the Jordanian governorates. The questionnaire was distributed in appropriate ways according to the characteristics of the sample, and the following table shows the results that were reached about the characteristics of the sample participants, and the iterations the percentages of demographic variables (gender, age in years, duration of ownership of the car) are as shown in the following table.

Table (1):Distribution of sample individuals according to demographic variables

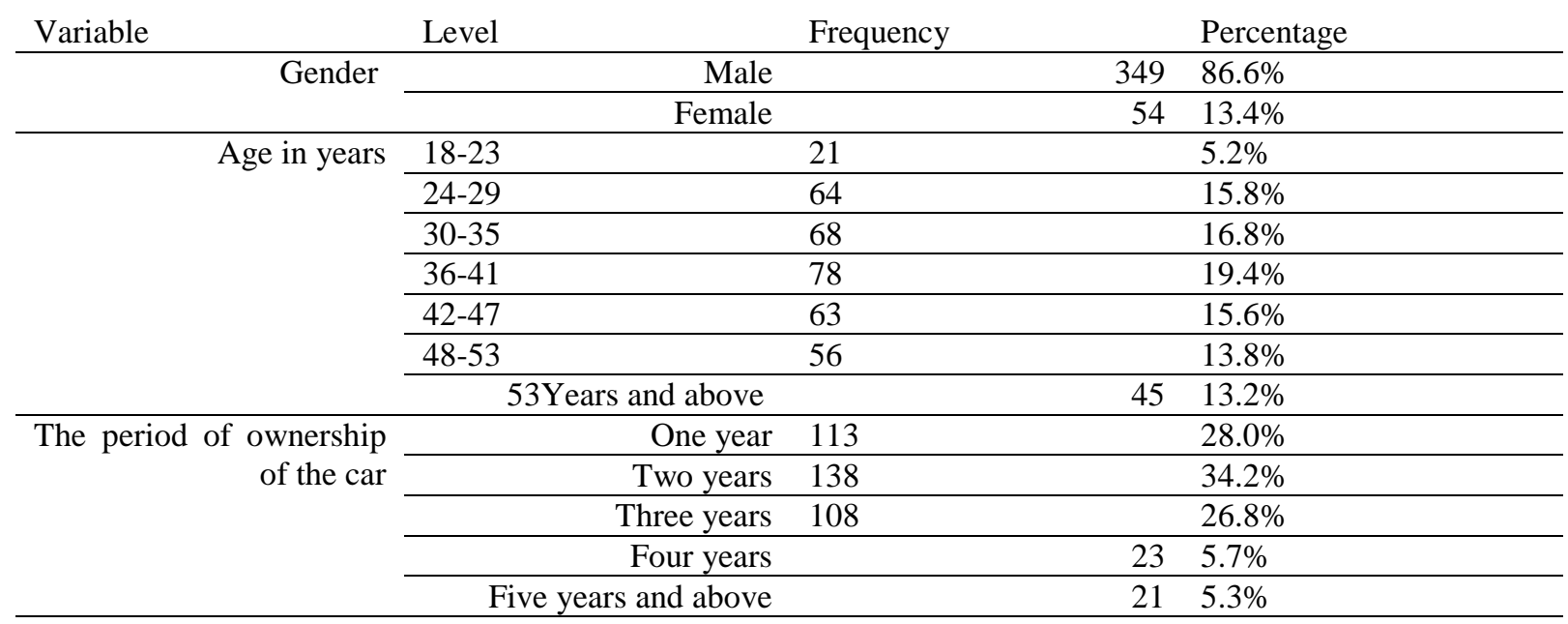

It was evident from the above table that the study sample consisted of (349) males at a rate of (86.6\%), and females (54) at a rate of (13.4\%), and it is clear from the table that those whose ages ranged between 36 years and 41 years were (78) individuals, at a rate of (19.4\%). And those whose ages range from 18 years and 23 years (21) at a rate of $(5.2 \%)$, and it is clear from the above table that the number of those who owned the car for a period of two years amounted to (138) at a rate of (34.2\%) and the number of those whose period of ownership of the car was more than five 21 years $(5.2 \%)$.

\section{Questionnaire Reliability}

To measure the reliability of the questionnaire, the researcher used (Cronbach's alpha equation) to verify the reliability of the tool. Table No. (2) Shows the reliability coefficients of the study tool.

Table(2): The values of the questionnaire reliability coefficients

\begin{tabular}{ccc}
\hline Factor & Number of paragraphs & Cronbach's alpha \\
\hline Home charging station & 4 & 0.77 \\
\hline External charging station (Alcazia) & 8 & 0.62 \\
\hline The charging station is at Workplace & 4 & 0.69 \\
\hline the Satisfaction of electric vehicle users & 3 & 0.84 \\
\hline General reliability of the questionnaire & $\mathbf{1 9}$ & $\mathbf{0 . 7 2}$ \\
\hline
\end{tabular}

It is evident from Table No. (2) That the general reliability coefficient for the study axes is good, reaching (0.72) for a total of (19) items of the questionnaire, while the reliability of the axes ranges between a minimum of 0.62 and a maximum of 0.84 as a maximum, and this indicates that the questionnaire has a high degree of Reliability. 


\section{Test results of the study hypothesis}

The study hypothesis regarding the Satisfaction of electric vehicle users with charging stations in Jordanwere tested using multiple linear regressions on SPSS, and the results were as follows:

Table (3): Tolerance and VIF results

\begin{tabular}{lll}
\hline Independent Variables & VIF & Tolerance \\
\hline Home charging station & 1.003 & 0.997 \\
\hline $\begin{array}{l}\text { External charging station } \\
\text { (Alcazia) }\end{array}$ & 1.001 & 0.899 \\
\hline $\begin{array}{l}\text { The charging station is at } 1.004 \\
\text { Workplace }\end{array}$ & & 0.765 \\
\hline
\end{tabular}

It appears from Table (3) that all values of VIF for all independent variables are less than 10, and Tolerance values are more than 0.05 , and this indicates the homogeneity of variance in the fields of study, and thus the possibility of applying multiple regression analysis.

Correlation coefficients were also extracted between the areas of charging station, to reveal a matrix of correlation coefficients between the areas of charging station and the Satisfaction of electric vehicle users in Jordan.

Table (4): Correlation coefficients between the fields of charging station and the Satisfaction of electric vehicle users in Jordan $(n=403)$

\begin{tabular}{ccccc}
\hline $\begin{array}{c}\text { The charging } \\
\text { station is at } \\
\text { Workplace }\end{array}$ & $\begin{array}{c}\text { External } \\
\text { charging station } \\
\text { (Alcazia) }\end{array}$ & $\begin{array}{c}\text { Home charging } \\
\text { station }\end{array}$ & \multicolumn{2}{c}{ Independent variables } \\
\cline { 4 - 5 } 0.69 & 0.731 & 0.653 & $\begin{array}{c}\text { Correlation } \\
\text { coefficient } \\
\text { Sig. }\end{array}$ & $\begin{array}{c}\text { Satisfaction of electric vehicle } \\
\text { users }\end{array}$ \\
0.000 & 0.000 & 0.003 & Sig.
\end{tabular}

It appears from Table (4) above that the correlation coefficients between the charging stations and the Satisfaction of electric vehicle users ranged between (0.653-0.731), all of which are positive, high and statistically significant values indicating a positive correlation between the charging stations and the Satisfaction of electric vehicle users in Jordan.

Testing the Null hypothesis: "There is no statistically significant effect in the charging stationon the Satisfaction of electric vehicle users in Jordan."

To test the null hypothesis, a multiple regression analysis was applied to reveal the effect of charging stations on the satisfaction of electric vehicle users in Jordan. Table (5) below illustrates this.

Table (5):Multiple regression analysis to reveal the effect of domains charging stations on the Satisfaction of electric vehicle users in Jordan.

\begin{tabular}{|c|c|c|c|c|c|c|c|c|c|}
\hline $\begin{array}{l}\text { Independent } \\
\text { Variable }\end{array}$ & $\begin{array}{c}\mathrm{T}- \\
\text { value }\end{array}$ & Sig. & $\begin{array}{c}\text { Standardized } \\
\text { Coefficients } \\
\text { Beta }\end{array}$ & $\begin{array}{c}\mathrm{R}- \\
\text { value }\end{array}$ & $\begin{array}{c}\mathrm{R}^{2}- \\
\text { value }\end{array}$ & $\begin{array}{c}\text { F- } \\
\text { value }\end{array}$ & Sig. & $\begin{array}{l}\text { Durbin- } \\
\text { Watson }\end{array}$ & Result \\
\hline $\begin{array}{l}\text { Home charging } \\
\text { station }\end{array}$ & 4.051 & 0.001 & 0.233 & 0.745 & 0.701 & 22.9 & 0.001 & 1.649 & Rejected \\
\hline $\begin{array}{l}\text { External charging } \\
\text { station (Alcazia) }\end{array}$ & 6.692 & 0.003 & 0.347 & & & & & & \\
\hline $\begin{array}{l}\text { The charging } \\
\text { station is at } \\
\text { Workplace }\end{array}$ & 5.007 & 0.000 & 0.199 & & & & & & \\
\hline
\end{tabular}

It appears from Table (5) above that the value of (F) amounted to (22.9) with statistical significance value (0.000), and the value of $(\mathrm{R})$ was (0.745), which represents the correlation coefficient between the independent variables and the dependent variable (The Satisfaction of electric vehicle users in Jordan).

The value of $(t)$ for the field of Home charging station was (4.051) with sig. (0.001), the value of (t) for the field of External charging station (Alcazia) was (6.692) with sig. (0.003), and the value of (t) for the field of the charging station is at Workplace was (5.007) with sig. (0.000). 
Thus, all the hypotheses of the sub-study, the main hypothesis, and the alternative main hypothesis are rejected, to become as follows: There is statistically significant effect in the charging station on the Satisfaction of electric vehicle users in Jordan.

\section{Discussion}

This paper concluded that there is an impact on the satisfaction of electric vehicle users in Jordan due to the charging stations and their types.We recommends to reducing the time spent charging electric vehicles at external charging stations, providing Workplace with charging stations for employees to facilitate time and cost, and increasing the quality of the mechanisms used in charging electric cars. As electricity prices for freight cars must be unified in all shipping places.

\section{References}

Borges, J., Ioakimidis, C. S., \&Ferrão, P. (2010). Fast charging stations for electric vehicles infrastructure. WIT Transactions on Ecology and the Environment, 130, 275-284.

Duvall, M., Knipping, E., Alexander, M., Tonachel, L., \& Clark, C. (2007). Environmental assessment of plug-in hybrid electric vehicles, Volume 1: Nationwide greenhouse gas emissions. Electric Power Research Institute, Palo Alto, CA, 1015325.

Eberle, U., \& Von Helmolt, R. (2010). Sustainable transportation based on electric vehicle concepts: a brief overview. Energy \& Environmental Science, 3(6), 689-699.

Falvo, M. C., Sbordone, D., Bayram, I. S., \&Devetsikiotis, M. (2014, June). EV charging stations and modes: International standards. In 2014 International Symposium on Power Electronics, Electrical Drives, Automation and Motion (pp. 1134-1139). IEEE.

Falvo, M. C., Sbordone, D., Bayram, I. S., \&Devetsikiotis, M. (2014, June). EV charging stations and modes: International standards. In 2014 International Symposium on Power Electronics, Electrical Drives, Automation and Motion (pp. 1134-1139). IEEE.

Fan, P., Sainbayar, B., \&Ren, S. (2015). Operation analysis of fast charging stations with energy demand control of electric vehicles. IEEE Transactions on Smart Grid, 6(4), 1819-1826.

He, F., Wu, D., Yin, Y., \& Guan, Y. (2013).Optimal deployment of public charging stations for plug-in hybrid electric vehicles. Transportation Research Part B: Methodological, 47, 87-101.

Kelly, L., Rowe, A., \& Wild, P. (2009, October).Analyzing the impacts of plug-in electric vehicles on distribution netWorkplaces in British Columbia. In 2009 IEEE Electrical Power \& Energy Conference (EPEC) (pp. 1-6). IEEE.

Khan, A., Memon, S., \&Sattar, T. P. (2018).Analyzing integrated renewable energy and smart-grid systems to improve voltage quality and harmonic distortion losses at electric-vehicle charging stations. IEEE Access, 6 , 26404-26415.

Lee, S., Iyengar, S., Irwin, D., \&Shenoy, P. (2016, November).Shared solar-powered EV charging stations: Feasibility and benefits.In 2016 Seventh International Green and Sustainable Computing Conference (IGSC) (pp. 1-8). IEEE.

Papadopoulos, P. (2012). Integration of electric vehicles into distribution NetWorkplaces (Doctoral dissertation, Cardiff University).

Sioshansi, R. (2012). OR Forum-modeling the impacts of electricity tariffs on plug-in hybrid electric vehicle charging, costs, and emissions. Operations Research, 60(3), 506-516.

Veneri, O., Ferraro, L., Capasso, C., \&Iannuzzi, D. (2012, October).Charging infrastructures for EV: Overview of technologies and issues.In 2012 Electrical Systems for Aircraft, Railway and Ship Propulsion (pp. 1-6). IEEE.

Wang, H., Huang, Q., Zhang, C., \& Xia, A. (2010, December).A novel approach for the layout of electric vehicle charging station.In The 2010 International Conference on Apperceiving Computing and Intelligence Analysis Proceeding (pp. 64-70). IEEE.

Xue, Y., Wu, J., Xie, D., Li, K., Zhang, Y., Wen, F., ...\& Yang, G. (2015). Multi-agents modelling of EV purchase willingness based on questionnaires. Journal of Modern Power Systems and Clean Energy, 3(2), 149-159.

Yang, W., Xiang, Y., Liu, J., \&Gu, C. (2017). Agent-based modeling for scale evolution of plug-in electric vehicles and charging demand. IEEE Transactions on Power Systems, 33(2), 1915-1925.

Yi, T., Cheng, X. B., Zheng, H., \& Liu, J. P. (2019).Research on Location and Capacity Optimization Method for Electric Vehicle Charging Stations Considering User's Comprehensive Satisfaction.Energies, 12(10), 1915.

Yong, J. Y., Ramachandaramurthy, V. K., Tan, K. M., \&Mithulananthan, N. (2015). Bi-directional electric vehicle fast charging station with novel reactive power compensation for voltage regulation. International Journal of Electrical Power \& Energy Systems, 64, 300-310. 